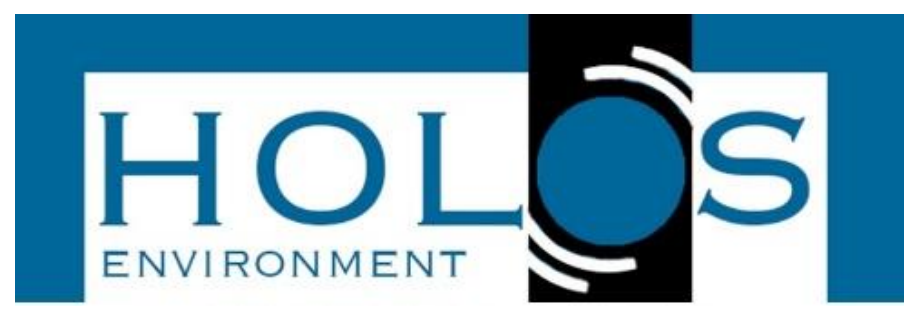

\title{
ANÁLISE DA VIABILIDADE TÉCNICA DA INCORPORAÇÃO DE AGREGADOS RECICLADOS EM CONCRETO
}

\section{TECHNICAL FEASEABILITY ANALYSIS OF THE USE OF RECYCLED AGGREGATES IN CONCRETE}

\author{
Thales Daniel dos Santos Fonseca ${ }^{1}$, Leopoldo Uberto Ribeiro Junior ${ }^{1}$, \\ Luciano Floriano Barbosa ${ }^{1}$
}

Artigo recebido em: 03/11/2016 e aceito para publicação em: 30/01/2018.

DOI: http://dx.doi.org/10.14295/holos.v18i1.12035

Resumo: Os resíduos da construção civil causam grande impacto ambiental, pois são gerados em grande volume e contaminam recursos naturais, porém ele apresenta grande capacidade de reciclagem, possibilitando sua reinserção no ciclo da construção civil, pela substituição dos agregados naturais por reciclados. Este trabalho tem como objetivo, comparar a resistência de concretos com substituição de agregados reciclados nos teores de $15 \%, 30 \%$ e $100 \%$, por meio do ensaio de compressão axial. A execução da pesquisa se dividiu, principalmente, em caracterização física dos agregados, dosagem dos traços de concreto pelo método do American Concrete Institute e o ensaio de compressão axial. A resistência à compressão aos 28 dias do concreto $100 \%$ reciclado e do concreto $100 \%$ natural se mostraram semelhantes, sendo 30,8 e $32,71 \mathrm{MPa}$, respectivamente, afirmando que a incorporação de agregados reciclados em novos concretos é viável.

Palavras-chave: Resíduos da Construção Civil. Dosagem de concreto. Gestão de resíduos. Reciclagem. Sustentabilidade.

\begin{abstract}
The civil construction waste causes a great environmental impact, because it is produced on a great volume and it pollutes natural resources, although it has a great recycling capability, allowing for the insertion of the solid waste, on the form of recycled aggregate, in the civil construction cycle again. This work has the objective of comparing the compressive strength of concretes using $15 \%, 30 \%$ and $100 \%$ of recycled aggregates. The research subdivided, mostly, on physical aggregates characterization, concrete dosage by the American Concrete institute method and the axial compression test. The compressive strength, on 28 days, of the $100 \%$ recycled and the $100 \%$ natural concretes were similar, with 30,8 and 32,71 , respectively, confirming the use of recycled aggregates as feasible .
\end{abstract}

Keywords: Construction Residue. Concrete Dosage. Waste Management. Recycling. Sustainability.

${ }^{1}$ FEPI-Centro Universitário de Itajubá. Emails: (fonseca.thales@yahoo.com, leopoldo junior@yahoo.com.br, lucianofb@fepi.br) 


\section{INTRODUÇÃO}

Os resíduos da construção civil (RCC), conhecidos popularmente por entulho, são gerados por reformas, demolições, reparos, manutenções e novas construções, perda de materiais, assim como o seu desperdício, devido ao aspecto artesanal da construção civil (ALMEIDA et al, 2015).

De acordo com Jacobi e Besen (2011), o RCC, causa degradação de corpos de água e da qualidade do solo, além de servir como abrigo para vetores de doenças e gerar obstruções de vias públicas.

O Brasil apresenta taxa de geração de 230 a $760 \mathrm{~kg}$ de RCC por habitante, ao ano, com valor médio de $510 \mathrm{~kg}$ por hab/ano, observando que grande parte dos municípios não possui usinas de reciclagem e por isso, a destinação final ocorre em aterros (PINTO, 1999).

Visando amenizar os impactos causados pelo RCC, foi criada a Resolução 307 do Conselho Nacional de Meio Ambiente que classifica os resíduos sólidos em diversas classes, sendo o RCC definido na classe A, passível de ser reciclado como agregado em concreto (CONAMA, 2002). De acordo com Marques et al (2013), o RCC apresenta grande capacidade de reciclagem, com, aproximadamente $90 \%$ de materiais recicláveis.

Os agregados reciclados são comumente utilizados em bases e sub-bases de pavimentos, devido aos menores requisitos, porém diversas pesquisas apontam que a resistência de concretos, não é afetada de forma significativa pelo uso de agregados reciclados, caso exista um maior controle em sua dosagem (RODRIGUES e FUCALE, 2014). Deste modo, este artigo tem o objetivo de estudar a viabilidade da incorporação de agregados reciclados de RCC em novos concretos, nos teores de $15 \%, 30 \%$ e $100 \%$, medindo a resistência por meio de ensaio de compressão axial aos 3, 7 e 28 dias de idade.

\section{MATERIAIS E MÉTODOS}

Os agregados reciclados foram adquiridos de uma empresa que realiza a britagem 
do RCC, para comercialização do agregado, enquanto que os agregados naturais e o cimento Portland Pozolânico (CP-Z-32), foram comprados no comércio local do município de Itajubá-MG.

A pesquisa foi realizada em cinco etapas:

- Levantamento das características físicas dos agregados

- Dosagem de concreto

- Execução dos traços

- Preparação dos corpos de prova

- Rompimento dos corpos de prova, aos 3, 7 e 28 dias.

Para a execução destas etapas foi necessário utilizar as normas técnicas da Associação Brasileira de Normas Técnicas (ABNT) dispostas no Quadro 01.

Quadro 01 - Ensaios técnicos

\begin{tabular}{|c|c|}
\hline Ensaios laboratoriais & Norma \\
\hline Ensaio de granulometria & NBR 248/03 \\
Massa específica de agregado graúdo & NM 52/09 \\
Massa específica de agregado miúdo & NM 23/01 \\
Massa específica do cimento & NM 45/06 \\
Massa unitária & NM 67/98 \\
Determinação da consistência pelo abatimento tronco de & cone \\
Moldagem de corpos de provas & NBR 5738/15 \\
Ensaio de compressão axial & NBR 5739/07 \\
Estimativa da resistência à tração/Módulo de & NBR $6118 / 14$ \\
\hline
\end{tabular}

Fonte: Autoria Própria

\subsection{Levantamento das características físicas dos agregados}

Para a caracterização foram realizados ensaios de massa específica e massa unitária solta nos agregados miúdos e graúdos, enquanto que o ensaio de massa unitária compactada foi realizado apenas nos agregados graúdos, pois são requisitos para a dosagem de concreto. A figura 01 apresenta os agregados utilizados na pesquisa. 
Figura 01 - (A) Agregados reciclados e (B) Agregados naturais

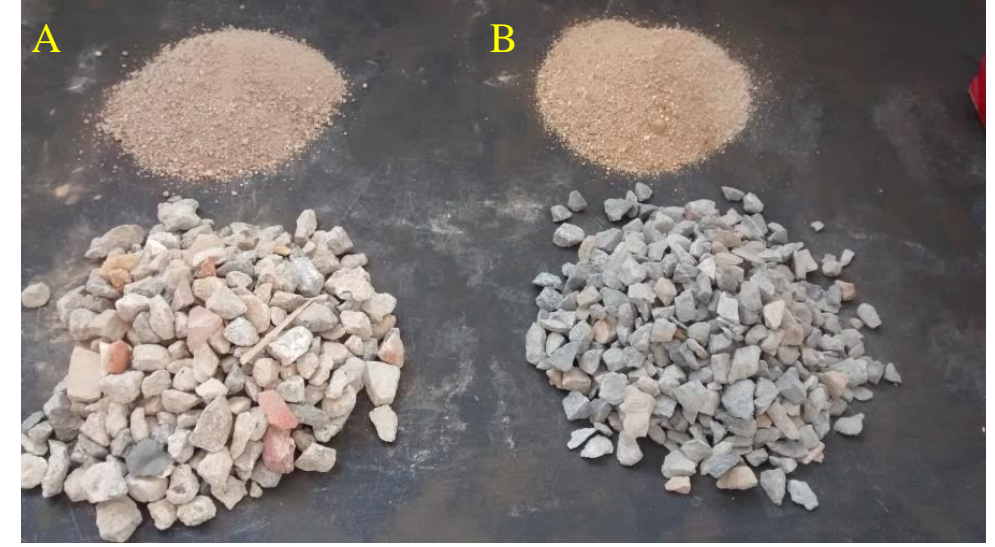

Fonte: Autoria Própria

\subsection{Dosagem de concreto}

Foi escolhido o método de dosagem do American Concrete Institute (ACl) 211.1 (Standard Practice for Selecting Proportions for Normal, Heavy Weght, and Mass Concrete), descrito em (MEHTA E MONTEIRO, 2008). Para a dosagem do concreto, com o intuito de padronizar a execução dos traços e comparar a variação da resistência proporcionada apenas pela diferença de agregados, foram adotados, conforme Araújo et al (2015), a relação água cimento de 0,50 e o abatimento de tronco de cone de 10 centímetros, admitindo a tolerância regulamentada por norma de 2 centímetros (ABNT, 2012). Os traços utilizados para a mistura dos componentes do concreto são demonstrados na tabela 01.

Tabela 01 - Traços desenvolvidos

\begin{tabular}{ccccccc}
\hline Tipo & $\begin{array}{c}\text { Cime } \\
\text { nto }\end{array}$ & $\begin{array}{c}\text { Areia } \\
\text { natural }\end{array}$ & $\begin{array}{c}\text { Areia } \\
\text { reciclada }\end{array}$ & $\begin{array}{c}\text { Brita } \\
\text { natural }\end{array}$ & $\begin{array}{c}\text { Brita } \\
\text { reciclada }\end{array}$ & Água \\
\hline Natural & 1 & 1,39 & - & 1,98 & - & 0,50 \\
$100 \%$ substituição & 1 & - & 1,50 & - & 1,12 & 0,50 \\
$15 \%$ substituição & 1 & 1,43 & - & 1,43 & 0,57 & 0,50 \\
$30 \%$ subsituição & 1 & 1,43 & - & 1,73 & 0,29 & 0,50 \\
\hline
\end{tabular}

Fonte: Autoria Própria

Observa-se que os valores apresentados se referem à quantidade necessária de materiais para a obtenção de concreto que respeite a relação água cimento utilizada e as características físicas levantadas dos materiais. 


\subsection{Execução dos traços}

Devido o agregado reciclado apresentar maior absorção de água, prosseguiu-se à saturação dos agregados graúdos, anteriormente à mistura. Esta compensação visa evitar que os agregados graúdos absorvam a água de amassamento e prejudiquem o concreto (FERREIRA; BRITO; BARRA, 2011). A saturação consistiu na adição da brita reciclada em um recipiente com água, por um período de 10 minutos, já que neste tempo, o agregado absorve aproximadamente $85 \%$ de sua absorção total, segundo Izquierdo et al. (2009). Após a compensação de absorção, os agregados foram retirados da água e adicionados à betoneira, para mistura.

A execução dos concretos consiste na mistura dos materiais de forma a respeitar os traços calculados, resultando no concreto com as características desejadas. A mistura dos componentes foi executada em ordem fixa, iniciada pela adição da brita e parte da água da mistura, seguida pela adição do cimento, finalizando com a adição da areia e o restante da água. Os materiais foram misturados até que o concreto não possuísse irregularidades em sua mistura e até que ele se mostrasse, visualmente, de forma homogênea. $O$ concreto foi liberado para a próxima etapa quando o ensaio de abatimento do tronco de cone apresentasse 10 centímetros de abatimento. Caso não apresente a medida requerida, o traço necessita ser corrigido pela adição de cimento e água, respeitando a relação água/cimento supracitada, assim como sua correção numérica após essas adições.

\subsection{Preparação dos corpos de prova}

Após a execução do concreto procedeu-se à moldagem dos corpos de prova, observando que foram utilizadas fôrmas cilíndricas metálicas de $10 \mathrm{~cm}$ de diâmetro e com $20 \mathrm{~cm}$ de altura, com fundo removível.

Foram executados quatro traços, o concreto de referência, sem adição de agregados reciclados, um traço com $15 \%$ de substituição do agregado graúdo natural por reciclado, o terceiro traço com substituição de $30 \%$ do agregado graúdo natural por reciclado e por último o concreto com $100 \%$ de uso de agregados reciclados, miúdo e 
graúdo.

A moldagem correspondeu a quatro corpos de prova para cada idade de rompimento ( 3,7 e 28 dias), totalizando 12 cilindros para cada traço e 48 no total.

Para evitar a evaporação de água, os cilindros foram cobertos com plástico filme PVC durante 24 horas. Com o período de repouso terminado foi possível desmoldar o concreto das fôrmas. Os corpos de prova foram submetidos à cura submersa em reservatório com solução saturada de cal (ABNT, 2015). A cura aos 28 dias é utilizada para o cálculo estrutural das estruturas de concreto armado e por isso a mais estudada na execução de concretos experimentais, enquanto que as demais idades de 3 e 7 dias demonstram a evolução de resistência até os 28 dias.

O capeamento foi realizado com argamassa, na proporção de duas medidas de areia para uma de cimento e aplicado nos corpos de prova com o objetivo de que a carga do ensaio seja aplicada de forma axial e uniforme.

\subsection{Rompimento dos corpos de prova}

O ensaio consiste na leitura da reação do concreto à carga aplicada pela prensa, de forma que o rompimento do corpo de prova é acusado pela diminuição da reação do concreto à aplicação de carga. O ensaio ocorre de forma que o carregamento é gradual e com velocidade de carregamento constante durante toda a duração do ensaio. Podese observar, na figura 02, a execução do ensaio de compressão em corpos de prova cilíndricos.

Figura 02 - Execução do ensaio de compressão

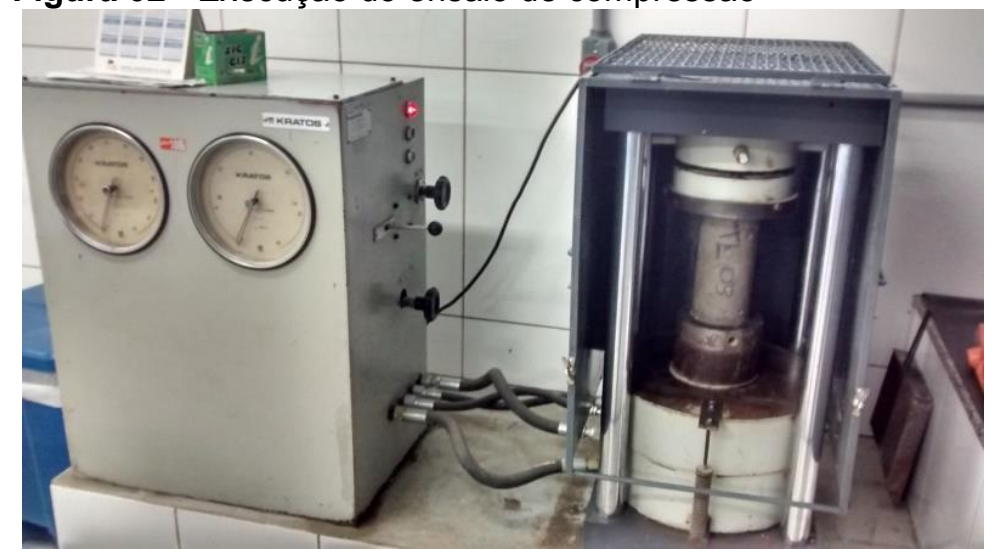

Fonte: Autoria Própria 


\section{RESULTADOS E DISCUSSÃO}

Os resultados da pesquisa consistiram na obtenção das características físicas dos agregados reciclados e as resistências obtidas por cada traço de concreto. As características físicas de cada tipo de agregado são demonstradas na tabela 02.

Tabela 02 - Caracterização física dos agregados

\begin{tabular}{ccccc}
\hline Característica & \multicolumn{2}{c}{ Reciclado } & \multicolumn{2}{c}{ Natural } \\
& Graúdo & Miúdo & Graúdo & Miúdo \\
\hline Massa unitária solta $\left(\mathrm{Kg} / \mathrm{m}^{3}\right)$ & 1144,25 & 1065,54 & 1320,63 & 1327,92 \\
Massa unitária & 1211,30 & - & 1402,26 & - \\
Compactada $\left(\mathrm{Kg} / \mathrm{m}^{3}\right)$ & 2,63 & 3,93 & 2,81 & 2,41 \\
Massa específica $\left(\mathrm{g} / \mathrm{cm}^{3}\right)$ & 2,63 & - & 0,33 & - \\
Absorção(\%) & 4,31 & - & &
\end{tabular}

Fonte: Autoria Própria

As características definem o tipo de material utilizado, sendo que a massa específica é um influenciador da resistência final do concreto, por isso, agregados com massa específica semelhante têm a tendência de obter resistência semelhante. A tabela 03 apresenta a granulometria aferida dos agregados utilizados:

Tabela 03 - Granulometria dos Agregados

\begin{tabular}{|c|c|c|c|c|}
\hline & $\begin{array}{c}\text { Miúdo } \\
\text { Reciclado }\end{array}$ & $\begin{array}{l}\text { Miúdo } \\
\text { Natural }\end{array}$ & $\begin{array}{c}\text { Graúdo } \\
\text { Reciclado }\end{array}$ & $\begin{array}{l}\text { Graúdo } \\
\text { Natural }\end{array}$ \\
\hline Peneira & \% Retida & \% Retida & \% Retida & $\%$ Retida \\
\hline 4,80 & 1,15 & 7,03 & 0,00 & 0,00 \\
\hline 2,40 & 3,29 & 7,70 & 0,00 & 0,00 \\
\hline 1,20 & 11,05 & 8,71 & 26,29 & 0,90 \\
\hline 0,60 & 30,69 & 18,60 & 53,83 & 53,11 \\
\hline 0,30 & 28,44 & 25,39 & 15,84 & 34,45 \\
\hline 0,15 & 15,44 & 23,57 & 3,24 & 11,30 \\
\hline Fundo & 9,94 & 9,00 & 0,80 & 0,25 \\
\hline $\mathrm{D} \max$ & 2,40 & 9,60 & 25,00 & 19,10 \\
\hline Mf & 2,32 & 2,46 & 7,21 & 6,89 \\
\hline Tipo & Areia Grossa & Areia Grossa & - & - \\
\hline
\end{tabular}

Os agregados miúdos foram enquadrados no tipo de areia grossa, de acordo com a NBR 248, por possuírem diâmetro maior que $2,4 \mathrm{~mm}$, apresentaram módulo de finura médio de 2,39, indicando uma dimensão de partículas próximas nos agregados 
reciclados e naturais. O módulo de finura dos agregados graúdos apresentou valor médio de 7,05, com uma variação de 0,22 nessa característica, indicando também similaridade entre os diâmetros das partículas dos agregados graúdos.

A elevada absorção dos agregados reciclados favorece a absorção da água da mistura, comprometendo concretos produzidos, por isso constata-se a necessidade de realizar a compensação pela pré-saturação dos agregados graúdos. A figura 03 demonstra alguns dos corpos de prova ensaiados.

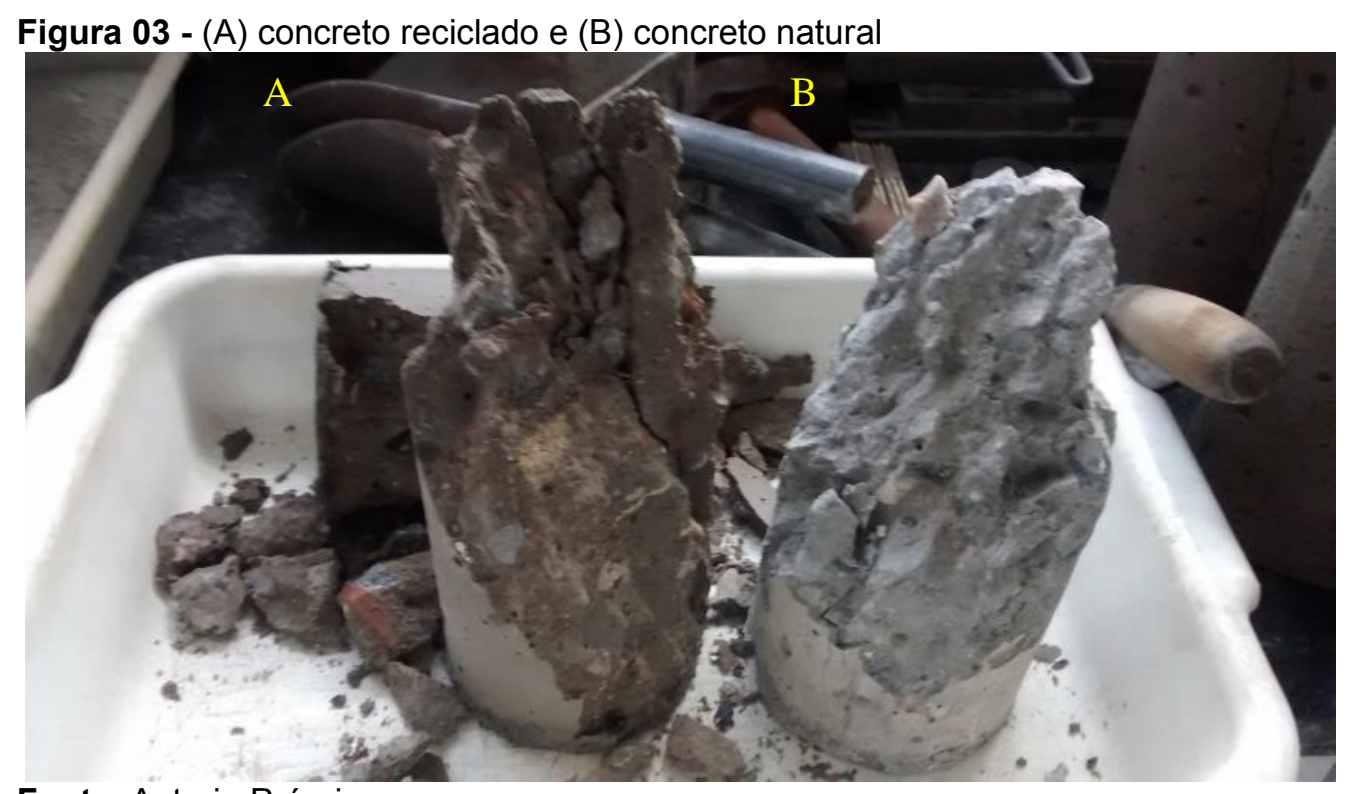

Fonte: Autoria Própria idades.

A tabela 04 demonstra as resistências à compressão, relacionados às suas

A avaliação estatística realizada foi o uso de média e desvio padrão, eliminando os corpos de prova que não atenderam a este intervalo, de forma que a resistência possua menor variação entre as amostras.

Nota-se que todos os corpos de prova ensaiados aos 28 dias atendem a exigência mínima da NBR 6118 que permite o uso de concreto com 20 Mpa com armadura passiva e concreto de $25 \mathrm{Mpa}$ com armadura ativa (ABNT, 2003).

O concreto com $100 \%$ de substituição dos agregados naturais por reciclados apresentou redução da resistência à compressão, na faixa de $6 \%$, valor este, mais próximo do concreto natural do que o encontrado por Vieira e Dal molin (2004) que encontraram redução de 14 \% na mesma proporção de substituição. 
Tabela 04 - Comparação do concreto reciclado com o concreto natural

\begin{tabular}{|c|c|c|c|c|}
\hline Tipo & $\begin{array}{l}\text { Idade } \\
\text { (dias) }\end{array}$ & $\begin{array}{c}\text { Resistência à } \\
\text { compressão } \\
\text { (MPa) }\end{array}$ & $\begin{array}{c}\text { Módulo } \\
\text { Elasticidade } \\
(\mathrm{GPa})\end{array}$ & $\begin{array}{l}\text { Resistência à } \\
\text { tração (MPa) }\end{array}$ \\
\hline \multirow{4}{*}{ Natural } & 3 & $19,50 \pm 1,41$ & 31,68 & 2,17 \\
\hline & 7 & $27,46 \pm 1,38$ & 34,12 & 2,73 \\
\hline & 28 & $32,71 \pm 1,44$ & 35,55 & 3,07 \\
\hline & 3 & $22,11 \pm 1,23$ & 32,52 & 2,36 \\
\hline \multirow[t]{3}{*}{ 15\% substituição } & 7 & $26,41 \pm 1,99$ & 33,45 & 2,58 \\
\hline & 28 & $38,09 \pm 1,30$ & 36,78 & 3,36 \\
\hline & 3 & $18,35 \pm 0,98$ & 31,30 & 2,09 \\
\hline \multirow[t]{3}{*}{$30 \%$ substituição } & 7 & $25,87 \pm 1,35$ & 33,66 & 2,62 \\
\hline & 28 & $33,93 \pm 0,57$ & 35,87 & 3,14 \\
\hline & 3 & $16,00 \pm 0,81$ & 30,48 & 1,90 \\
\hline \multirow[t]{2}{*}{$100 \%$ substituição } & 7 & $22,03 \pm 0,88$ & 32,50 & 2,36 \\
\hline & 28 & $30,80 \pm 0,70$ & 35,04 & 2,95 \\
\hline
\end{tabular}

Fonte: Autoria Própria

Vale salientar que apesar do concreto com 100\% de substituição apresentar resistência acima da mínima indicada para uso estrutural, a diminuição da resistência é característica do material reciclado e por isso, o mesmo deve ser estudado anteriormente ao uso estrutural.

A resistência à tração estimada mostrou que os concretos reciclados e naturais pertencem ao mesmo grupo e por isso o uso dos agregados reciclados não impactou nesta característica. O módulo de elasticidade estimado apresentou valores similares, com exceção do módulo de elasticidade do concreto com $15 \%$ de substituição que apresentou uma melhora de resultado, relacionado ao aumento da resistência à compressão.

Neste trabalho foi constatada a influência da menor massa especifica dos agregados graúdos na resistência a compressão final do concreto com 100\% de substituição, ligação demonstrada também por Gomes et al (2015) que encontrou uma relação diretamente proporcional entre as duas características. É recomendado o uso da massa específica dos agregados para avaliar sua qualidade, já que quanto maiores seus valores, maior a tendência de desempenho superior nos concretos produzidos.

Os valores de 15 e $30 \%$ de substituição beneficiaram o concreto reciclado, com destaque para o teor de 15\%, nota-se que Pereira; Medeiros; Levy (2012) encontraram 
maiores desempenhos em concretos com substituição de $20 \%$.

Observa-se que o concreto com $15 \%$ de incorporação apresentou um aumento de resistência de $15 \%$, resultado similar ao de Araújo et al (2016) que encontrou aumento de $13 \%$ na incorporação de $19 \%$ de agregados reciclados.

O aumento da resistência do concreto reciclado, na proporção de $15 \%$ e $30 \%$, se dá, provavelmente, pela maior porosidade do agregado reciclado que proporciona maior absorção da água livre do concreto e consequentemente o aumento da resistência (OTOKO, 2014). O uso de $100 \%$ do agregado reciclado causa a diminuição em excesso da água da mistura, também devido a maior porosidade do agregado e assim há a diminuição de sua resistência. (KALAK, 2009).

\section{CONCLUSÃO}

Considerando a resistência a compressão, em conjunto com a resistência à tração e o módulo de elasticidade estimados das amostras estudadas, o concreto reciclado pode possuir comportamento semelhante ao natural, logo o uso estrutural dos agregados reciclados é possível desde que as características físicas dos concretos produzidos sejam avaliadas previamente.

Conforme os ensaios desenvolvidos, pode-se observar que o uso de $15 \%$ de agregados reciclados apresentou os melhores resultados de resistência, enquanto que foi constatada diminuição de $6 \%$ da resistência à compressão de concretos $100 \%$ reciclados, em relação ao concreto de referência.

Com os resultados obtidos é possível afirmar que o RCC possui uma destinação mais adequada do que o descarte em aterros sanitários.

\section{AGRADECIMENTOS}

Agradeço à Fundação de Amparo à Pesquisa de Minas Gerais (FAPEMIG), pela concessão de bolsa de iniciação científica e pela oportunidade de pesquisa durante a graduação. 
Agradeço à FEPI- Centro universitário de Itajubá, pelo uso do laboratório de materiais de construção civil para os ensaios científicos.

Agradeço à Alpha Ambiental pela doação dos agregados reciclados utilizados na pesquisa e pela visita às suas instalações.

\section{REFERÊNCIAS}

ABNT. NBR 5738: concreto - procedimento para moldagem e cura de corpos de prova. Rio de Janeiro: ABNT, 2015.

ABNT. NBR 6118: projeto de estruturas de concreto-procedimento. Rio de Janeiro: ABNT, 2014.

ABNT. NBR 7212: execução de concreto dosado em central - procedimento. Rio de Janeiro: ABNT, 2012.

ALMEIDA, R. R. P. et al. Identificação e análise dos impactos ambientais gerados na indústria da construção civil. Informativo Técnico do Semiárido, Pombal, v. 9, n. 1, p. 39-46, jan. 2015.

ARAÚJO, D. L. et al. Influência de agregados reciclados de resíduos de construção nas propriedades mecânicas do concreto. Revista Eletrônica de Engenharia Civil, [s.l.], v. 11, p. 16-34, fev. 2016.

CONAMA. Resolução no 307, de 05 de julho de 2002.Brasília: Ministério do Meio Ambiente., 2002.

FERREIRA, L; DE BRITO, J; BARRA, M. Influence of the pre-saturation of recycled coarse concrete aggregates on concrete properties. Magazine of Concrete Research, [s.I.]v. 63, n. 8, p. 617-627, ago. 2011.

GOMES, P. C. C et al. Obtenção de concreto leve utilizando agregados reciclados. Ambiente Construído, Porto Alegre, v. 15, n. 3, p. 31-46, 2015.

IZQUIERDO, I. S. et al. Uso de RCDs como áridos reciclados y su empleo en hormigones estructurales. Revista Minerva, [s.I.], v. 6, n. 3, p. 237-245. 2009.

JACOBI, P. R; BESEN, G. R. Gestão de resíduos sólidos em São Paulo: desafios da sustentabilidade. Estudos Avançados, São Paulo, v. 25, n. 71, p.135-158, jan. 2011.

KALAK, F. S. Use of crushed bricks as coarse aggregate in concrete. Tikrit Journal of Engineering Science (TJES), v. 16, n. 3, p. 64-69. Sep. 2009.

MARQUES, O. et al. Resíduos de construção civil: geração e alternativas para reciclagem em um canteiro de obras de pequeno porte. Engenharia Ambiental: Pesquisa e Tecnologia, Espírito Santo do Pinhal, v. 10, n. 2, p. 143-156. Mar. 2013.

MEHTA, P. K; MONTEIRO, P. J. M. Concreto: microestrutura, propriedades e materiais. 3. ed. São Paulo: Ibracon, 2008. 674 p. 
OTOKO, G. R. Use of crushed clay bricks as aggregate in concrete. Int. J. Eng. Technol. Res, v. 2, p. 1-9. Apr. 2014.

PEREIRA, E; MEDEIROS, M. H. F.; LEVY, S. M. Durabilidade de concretos com agregados reciclados: uma aplicação de análise hierárquica. Ambiente Construído, Porto Alegre, v. 12, n. 3, p. 125-134, jul. 2012.

PINTO, T. P. Metodologia para a gestão diferenciada de resíduos sólidos da construção urbana. 1999.189 p. Tese (Doutorado Em Engenharia) Universidade Politécnica de São Paulo. São Paulo 1999.

RODRIGUES, C. R. S.; FUCALE, S. Dosagem de concretos produzidos com agregado miúdo reciclado de resíduo da construção civil. Ambiente Construído, Porto Alegre, v. 14, n. 1, p. 99 111, Jan. 2014.

VIEIRA, G. L; DAL MOLIN, D. C. C. Viabilidade técnica da utilização de concretos com agregados reciclados de resíduos de construção e demolição. Ambiente Construído, Porto Alegre, v. 4, n. 4, p. 47-63. 2004 